\title{
KOMPARATIVNA ANALIZA EDUKACIJE MENADŽERA U KINEZIOLOŠKOJ REKREACIJI I OSTALIM DJELATNOSTIMA
}

\author{
Dragomir Gabrićc ${ }^{14}$, Sanela Škorićc ${ }^{15}$, Marko Mornar Jelavić ${ }^{16}$
}

UDC / UDK: 331.36-057.17:796.075:796.035(497.5)

JEL classification / JEL klasifikacija: Z29, I29, M54

DOI: https://doi.org/10.22598/pi-be/2020.14.2.107

Preliminary communication / Prethodno priopćenje

Received / Primljeno: April 1, 2020 / 1. travnja 2020.

Accepted for publishing / Prihvaćeno za tisak: October 5, 2020 / 5. listopada 2020.

\section{Sažetak}

Ciljevi: Usporediti edukacije menadžera u kineziološkoj rekreaciji (UZR) $u$ odnosu na menadžere u drugim djelatnostima (OD) te utvrditi žele li više usavršavati svoja znanja.

Metodologija: 192 ispitanika (66.7\% muškaraca, prosječne životne dobi 40 godina) su osobe na vodećim pozicijama organizacija. Klasificirani su u dvije skupine (UZR, OD) $i$ anketirani pomoću modificiranog upitnika prema osnovnim podacima o menadžeru (spol, dob, visina stručne spreme, razina menadžmenta na kojoj se nalazi, duljina radnog staža) te učestalosti pohađanja programa edukacije (niti jednom, jednom, više puta, stalno) i motiviranosti za nastavkom usavršavanja (stručnog, ekonomskog, organizacijskog, menadžment, informatičkog, sociološkog, psihološkog te ophođenja s ljudima).

Rezultati: Prema učestalosti pohađanja programa edukacije unutar poduzeća, najveća razlika među skupinama je kod onih učesnika koji su stalno pohađali edukacijske programe u korist $O D(3.2 \%$ vs $21.2 \%)$. Prema programu trajnog obrazovanja $i$ usavršavanja menadžera, najveća razlika među skupinama je u želji stjecanja ekonomskih znanja (11.8\% vs 34.3\%), a nešto manje u domeni psiholoških (19.4\% vs $37.4 \%)$ i socioloških znanja (10.8\% vs 17.2\%) u korist menadžera skupine OD (za sve $P<0.05)$.

\footnotetext{
${ }^{14}$ Dragomir Gabrić, MSc, Dragomir Gabrić d.o.o., E-mail: gabric@webtirol.com

${ }^{15}$ Sanela Škorić, PhD, Associate Professor at the Faculty of Kinesiology, University of Zagreb, Croatia

${ }^{16}$ Marko Mornar Jelavić, MD, Polyclinic for Cardiovascular Disease Prevention and Rehabilitation, Zagreb, Croatia
} 
Ograničenja: Istraživački proces bio je limitiran veličinom uzorka uzrokovan Zakonom o zaštiti osobnih podataka i brojem zaposlenih koji je bio na donjoj granici traženog pogotovo u djelatnostima vezanima uz kineziološku rekreaciju.

Originalnost $i$ znanstveni doprinos: prvo istraživanje u Hrvatskoj koje uspoređuje trenutnu i motiviranost za buduću edukaciju menadžera u kineziološkoj rekreaciji i drugim djelatnostima. Novitet i vrijednost ovog istraživanja ukazuje upravo na važnost edukacije menadžera općenito i razvijanje svjesnosti o ekonomskim znanjima koja iтаju ključnu ulogu u uspješnom upravljanju kineziološko-rekreacijskom organizacijom.

Ključne riječi: ekonomska znanja, menadžment, menadžerska znanja, kineziološka rekreacija, programi obrazovanja.

\section{UVOD}

U svakom sektoru postizanje uspjeha bilo koje organizacije uvelike ovisi o njezinim zaposlenicima, osobito menadžerima, pa je važno da poduzeće osigura učinkovite menadžere u skladu s konkurencijom na tržištu. Organizacije moraju biti svjesne važnosti programa obrazovanja u menadžmentu, te stjecanja znanja menadžera i njihovih kompetencija. Ključni element planiranja karijere i razvoja zaposlenika, osobito menadžera je postavljanje ciljeva. Stoga, veoma je značajno da programi obrazovanja podržavaju menadžere na način da poboljšaju njihov rad, umjesto da samo povećavaju njihove radne kompetencije (Gerbman, 2000). Važno je dati priliku zaposlenicima da svoj posao obavljaju na bolji način, a ako im je potrebna pomoć, organizacije im moraju pružiti odgovarajuće alate za obavljanje posla. Programi obrazovanja također pomažu zaposlenicima da steknu konceptualne vještine razmišljanja na drugačiji način (Gerbman, 2000).

Menadžment se sastoji od planiranja, organiziranja, aktiviranja i kontroliranja radi utvrđivanja i ostvarivanja ciljeva uporabom ljudi i resursa. Najvažniji aspekt s kojeg se promatra menadžment je onaj procesni, odnosno poimanje menadžmenta kao procesa. Utemeljitelj procesne teorije menadžmenta je Henri Fayol, koji je dao prvu klasifikaciju funkcija menadžmenta i smatra se ocem teorije menadžmenta (Fayol, 1949). On menadžment vidi kao proces i transformaciju ,inputa u outpute”, a taj transformacijski proces čine funkcije menadžmenta. Temeljni zadatak menadžmenta u tom procesu je maksimizirati output $\mathrm{u}$ odnosu na input.

Uloga menadžera u počecima razvoja organizacije pripada poduzetniku, odnosno vlasniku, koji je ujedno i nositelj izvršne funkcije. Razvojem organizacije dolazi do veće podjele rada, a time i do potrebe za menadžmentom. Korijeni menadžmenta su tamo gdje vlasnici prepuštaju određene aktivnosti drugima jer ih nisu u mogućnosti sami obavljati (Drucker, 1961). Najvažniji aspekt s kojeg se promatra menadžment je onaj procesni, odnosno poimanje menadžmenta kao procesa. Utemeljitelj procesne teorije menadžmenta je Fayol, H. ((1949) General and Industrial Management), koji je dao prvu klasifikaciju funkcija menadžmenta i smatra se ocem teorije menadžmenta. On menadžment vidi kao proces i transformaciju "inputa u outpute", a taj transformacijski 
proces čine funkcije menadžmenta. Temeljni zadatak menadžmenta u tom procesu je maksimizirati output u odnosu na input.

Menadžeri se nalaze na različitim menadžerskim pozicijama, u različitim organizacijama i institucijama profitnog i neprofitnog sektora te navedenim funkcijama pristupaju s različitim temeljnim obrazovanjem. Oni moraju posjedovati tri temeljne vrste znanja i vještina i to: tehnička znanja i vještine, znanja i vještine u ophođenju s ljudima te konceptualna znanja i vještine, kojima se mogu dodati i tzv. vještine oblikovanja (Koontz, Weihrich and associates, 1998).

Ulaganje u znanje zaposlenika i menadžera danas je važnije nego ikad, uglavnom kao posljedica globalizacijskih procesa i potrebe za inovacijama koje osiguravaju dugoročan rast. Povećanjem složenosti posla i razinom odgovornosti povećavaju se i zahtjevi za potrebnim znanjima bitnim za upravljanje kompleksnim organizacijama. Odnos razine znanja i pozicije menadžera govori da viši menadžment mora posjedovati više općih znanja, a manje specifičnih. U slučaju nižeg menadžmenta taj odnos omjera je obratan. Uspješan menadžer mora posjedovati funkcionalna, sistemska i znanja iz situacijskih analiza jer upravo ona omogućuju menadžeru obavljanje osnovne menadžerske funkcije - planiranje, organiziranje, vođenje i kontrolu. Bitno je istaknuti da tvrtke moraju razvijati vlastiti sustav znanja koji proizlazi iz prakse. Najčešće su stručna znanja menadžera produkt obrazovanja i upravo ta znanja su podložna zastarijevanju. Prema tome nužan je kontinuitet obnavljanja i razvoj istih kako bi se održao kvalitet ljudskih potencijala i sposobnost za ostvarenje zadanih ciljeva.

Vještine se definiraju kao usvojene sposobnosti nužne za izvođenje određenih zadataka. Efikasni menadžeri moraju imati sljedeće vještine: tehničke vještine, vještine odnosa s ljudima, komunikacijske vještine te konceptualne vještine (Koontz, Weihrich and associates, 1998).

Menadžment u sportu smatra se relativno „mladom“ znanstvenom disciplinom. Prvi su se programi menadžmenta u sportu počeli uvoditi u programe visokoobrazovnih institucija 1960-ih godina. I prije je postojao menadžment u sportu, ali se on nije sustavno tretirao niti teoretski niti u praksi. Može se definirati kao znanost i praksa svih ljudi, aktivnosti, tvrtki ili organizacija koje su uključene u proizvodnju, olakšavajući, promovirajući ili organizirajući bilo koju tvrtku ili proizvod povezanu sa sportom (Pitts i sur, 2014). Sastoji se od nekoliko procesa vezanih za donošenje odluka (svojstven svim procesima), planiranje, organiziranje, upravljanje kadrovima, vođenje, motiviranje, komuniciranje te kontroliranje, a u svrhu postizanja postavljenih ciljeva organizacije (Quaterman i Li, 1998). Sportski menadžment je bilo koja kombinacija vještina povezanih sa planiranjem, organiziranjem, upravljanjem, kontrolom, financiranjem, vođenjem i vrednovanjem unutar konteksta organizacije ili odjela čiji su primarni proizvod ili usluga povezani sa sportom i/ili fizičkom aktivnošću (De Sensi i sur, 1990). Konačno, sportski menadžment podrazumijeva poseban menadžment povezan sa sportskim aktivnostima čija je osnovna zadaća koordinacija sportskih aktivnosti (Bartoluci i Škorić, 2009). Sportski menadžeri odgovorni su za postizanje ciljeva organizacije kroz efikasnu i djelotvornu upotrebu resursa. Efektivan menadžer je onaj koji radi prave stvari na putu ostvarenja cilja tj. ima ispravnu strategiju. Resursi kojima 
upravlja mogu biti ljudski, financijski, materijalni i informacijski (Lussier i Kimball, 2014).

Menadžeri u sportu su sve manje "vješti trgovci”, a sve se više bave strategijom razvoja i tvorci su uspješnosti cijele sportske organizacije ili jednog sportskog pothvata. Pogrešno je mišljenje da su oni samo uspješni sportski "biznismeni”, jer menadžeri se u isto vrijeme, da bi dostigli postavljene ciljeve, bave konceptualnim problemima sportskih organizacija. Također, oni moraju posjedovati osnovna stručno-tehnička znanja iz područja sporta. Oni moraju predviđati, planirati, organizirati, rukovoditi, baviti se kadrom i kontrolirati primarne procese u treningu i natjecanju. Svaka njihova aktivnost orijentirana je na mnoštvo vidljivih i nevidljivih međuljudskih odnosa, koji su po pravilu suptilni, ali i konfliktni. Ipak, menadžeri u sportu svojim djelovanjem prvenstveno moraju doprinijeti razvoju sporta, što je njihov osnovni cilj.

Draganov (2016) bavi se istraživanjem tendencija u zahtjevima koji se stavljaju pred sportske menadžere u odnosu na njihove osobne karakteristike, vještine, vrijednosti i stavove te na koji način dolazi do sinkronizacije postavljenih zahtjeva i stvarnog stanja. U istraživanju su sudjelovali menadžeri i voditelji koji rade u sportskim klubovima, menadžerskim agencijama te privatnim sportskim i fitnes centrima. Cilj istraživanja je bio utvrditi mogućnosti unapređenja i upravljanja sportskim i komercijalnim organizacijama kao i utvrđivanje mogućnosti prilagodbe obrazovnog procesa potrebama sportskog tržišta. Rezultati istraživanja su pokazali da sportski menadžeri imaju dovoljno stručnog i tehničkog znanja, ali im je deficitno znanje na području ekonomije, menadžmenta, upravljanja ljudskim potencijalima te na području psihologije, informacijskih znanosti i sociologije.

Do interesantnih spoznaja došao je i Thomas Apitzsch (2012). godine proučavajući na visokoj sportskoj školi u Kölnu profile kompetencija trenera i sportskih menadžera u vrhunskom sportu. On naglašava da razvoj svih kompetencija pridonosi uspjehu, a prema rezultatima njegova istraživanja sociološka znanja i kompetencija vezana uz to je danas od ključnog značaja te će njezin značaj u budućnosti još više dobivati na važnosti. Konkretna praktična primjena stečenih znanja najveći je izazov na svim razinama menadžmenta.

Kineziologija je znanstveno područje koje proučava opće zakonitosti upravljanja procesa vježbanja i učinka tih procesa, zakona efikasnih kretanja i zakona za reguliranje transformacije antropoloških obilježja, sposobnosti i znanja pod utjecajem procesa vježbanja (Andrijašević, 2010). Kineziološka rekreacija je primijenjena znanstvena disciplina u području kineziologije koja ustanovljava i definira način primjene sportskorekreacijskih sadržaja i programa tjelesne aktivnosti radi očuvanja i unapređivanja ljudskog zdravlja. Menadžeri u kineziološkoj rekreaciji koriste menadžerske tehnike koje su vrlo slične onima kojima se koriste menadžeri drugih organizacija nevezanih uz sport. Postoji potreba za sustavnijom organizacijom obrazovnih i edukacijskih programa vezanih uz različite razine menadžmenta u kineziološkoj rekreaciji (Freericks, 2010).

Ciljevi ovog istraživanja su: (1) Usporediti učestalost pohađanja programa edukacije menadžera $u$ kineziološkoj rekreaciji u odnosu na menadžere $u$ drugim djelatnostima i (2) Utvrditi žele li kineziološki i ostali menadžeri ubuduće više usavršavati svoja znanja. 


\section{METODOLOGIJA ISTRAŽIVANJA}

\subsection{Ispitanici i prikupljanje podataka}

Ispitanici su osobe na vodećim pozicijama organizacija, selektirani iz baze podataka Hrvatske gospodarske komore (HGK) prema Nacionalnoj klasifikaciji djelatnosti (NKD) iz 2007. godine. Selekcija je provedena poštujući slijedeće kriterije: 1. Da je u trenutku provođenja istraživanja tvrtka aktivna, odnosno da aktivno posluje.

2. Da je broj zaposlenih $\geq 3$ prema Godišnjem Financijskom Izvještaju (GFI) iz 2016. godine.

Selektirane su dvije grupe:

1. Umjetnost, zabava i rekreacija (UZR). Osobe na čelnim pozicijama u organizacijama koje pripadaju sportsko-rekreacijskom sektoru (R93 - Sportske djelatnosti te zabavne i rekreacijske djelatnosti). Preliminarnom analizom utvrđen je broj tvrtki koje zadovoljavaju kriterije. Potencijalni uzorak sastojao se od 211 subjekata (to su fitness centri, tenis, squash i badminton centri, ronilački klubovi, igraonice te marine). Očekivao se $50 \%$ odaziv odabranih organizacija. Ukupno su prikupljena 93 valjano popunjena upitnika, odnosno $44 \%$.

2. Ostale djelatnosti $(O D)$. Osobe na čelnim pozicijama u organizacijama koje pripadaju ostalim uslužnim djelatnostima: trgovina na veliko i malo, popravak motornih vozila i motocikala; prijevoz i skladištenje; djelatnosti pružanje smještaja te priprema i posluživanja hrane; informacije i komunikacije; financijske djelatnosti i djelatnosti osiguranja; poslovanje nekretninama; stručne, znanstvene i tehničke djelatnosti; administrativne i pomoćne uslužne djelatnosti; obrazovanje; djelatnosti zdravstvene zaštite i socijalne skrbi; ostale uslužne djelatnosti. Uzorak organizacija koje pripadaju ostalim djelatnostima, izabran je poštujući iste kriterije sportsko-rekreacijskog sektora. Tom selekcijom dobiveno je ukupno 7573 subjekata. Za potrebe rada, slučajnim odabirom izabrano je 750 poduzeća $(10 \%)$. Da bi se zadovoljile potrebe komparacije, bio je potreban odaziv 10 do $15 \%$. Stvarni odaziv je bio 13,2\%, što znači 99 valjano popunjenih upitnika.

U obje grupe dobiveno je ukupno 192 ispitanika, koji su anketirani modificiranim upitnikom (Bahtijarević-Šiber, Sikavica, 2002) prema osnovnim podacima o menadžeru (spol, dob, visina stručne spreme, razina menadžmenta na kojoj se nalazi, duljina radnog staža) te učestalosti pohađanja programa edukacije (niti jednom, jednom, više puta, stalno) i motiviranosti za nastavkom usavršavanja (stručnog, ekonomskog, organizacijskog, menadžment, informatičkog, sociološkog, psihološkog te ophođenja s ljudima).

\subsection{Statistička analiza}

Dobivene vrijednosti prikazane su apsoultnim brojem (N) i postotkom (\%). U statističkoj analizi korišten je $\chi^{2}$-test $\mathrm{s}$ Fischerovom korekcijom za male uzorke. Razina statističke značajnosti definirana je s $P<0.05$. Svi podaci analizirani su u statističkom programu SPSS (verzija 23.0., proizvođač IBM, USA). 


\section{REZULTATI}

Od ukupno 192 ispitanika, bilo je 128 (66.7\%) muškaraca i 64 (33.3\%) žene, prosječne životne dobi 40 godina. U skupini UZR, broj zaposlenih menadžera životne dobi od 30-60 godina po desetljećima pada, dok je je u istom razdoblju u skupini OD obratno. Više od polovice svih ispitanika ima visoku stručnu spremu $(53,65 \%)$. Najveći dio ispitanika je na najvišoj razini menadžmenta $(71,4 \%)$, a kod najvećeg dijela ovo nije prvo radno mjesto $(91,1 \%)$.

Dodatnom analizom dobiveni su slijedeći rezultati:

1. S obzirom na učestalost pohađanja programa edukacije unutar poduzeća kod niti jednom i više puta gotovo da nema razlike među dvjema skupinama (Tablica 1). Kod onih koji su samo jednom pohađali edukaciju razlika je u korist UZR (24.7 vrs $7.1 \%$, $P<0.05)$. No, najveća razlika je kod onih učesnika koji su stalno pohađali edukacijske programe u korist OD (3.2 vrs $21.2 \%, P<0.05)$. To je ključna razlika među skupinama i ukazuje da menadžeri u OD učestalije pohađaju programe obrazovanja unutar poduzeća (kućni trening) u odnosu na menadžere skupine UZR.

2. Po pitanju programa obrazovanja i usavršavanja menadžera, skupina UZR najviše teži stjecanju znanja iz područja menadžmenta $(61.3 \%)$, zatim znanja ophođenja s ljudima (54.8\%), te stručnih (47.3\%), informatičkih (41.9\%), organizacijskih $(33.3 \%)$, psiholoških (19.4\%), ekonomskih (11.8\%) i socioloških znanja (10.8\%) (Tablica 2).

Skupina OD najviše polaže u stjecanje znanja iz područja menadžmenta $(63.6 \%)$, zatim znanja ophođenja s ljudima (56.6\%), te stručna $(48.5 \%)$, informatička $(44.4 \%)$, organizacijska (39.4\%), psihološka (37.4\%), ekonomska (34.3\%) i sociološka znanja (17.2\%) (Tablica 2).

Najveća razlika među skupinama je u želji stjecanja ekonomskih znanja (11.8 vrs $34.3 \%, P<0.05)$, a nešto manje u domeni psiholoških $(19.4 \%$ vrs $37.4 \%, P<0.05)$ i socioloških znanja $(10.8 \%$ vrs $17.2 \%, P<0.05)$ u korist menadžera skupine OD.

Tablica 1. Pohađanje programa obrazovanja i usavršavanja menadžera

\begin{tabular}{|c|c|c|c|c|c|}
\hline \multirow{2}{*}{\multicolumn{3}{|c|}{$\begin{array}{l}\text { Jeste li ste kao menadžer pohađali neki } \\
\text { od niže navedenih programa } \\
\text { obrazovanja } \\
\text { i usavršavanja menadžera: }\end{array}$}} & \multicolumn{3}{|c|}{ Djelatnosti po NKD-u } \\
\hline & & & \multicolumn{2}{|c|}{\begin{tabular}{l|l} 
UZR & OD
\end{tabular}} & Ukupno \\
\hline \multirow{10}{*}{$\begin{array}{l}\text { Obrazovanje } \\
\text { unutar poduzeća } \\
\text { (tzv. kućni } \\
\text { trening) }\end{array}$} & \multirow[t]{2}{*}{ NIJEDNOM } & $\mathrm{N}$ & 23 & 23 & 46 \\
\hline & & $\%$ & $24,7 \%$ & $23,2 \%$ & $24,0 \%$ \\
\hline & \multirow[t]{2}{*}{ JEDNOM } & $\mathrm{N}$ & 23 & 7 & 30 \\
\hline & & $\%$ & $24,7 \%$ & $7,1 \%$ & $15,6 \%$ \\
\hline & \multirow[t]{2}{*}{ VIŠE PUTA } & $\mathrm{N}$ & 44 & 48 & 92 \\
\hline & & $\%$ & $47,3 \%$ & $48,5 \%$ & $47,9 \%$ \\
\hline & \multirow[t]{2}{*}{ STALNO } & $\mathrm{N}$ & 3 & 21 & 24 \\
\hline & & $\%$ & $3,2 \%$ & $21,2 \%$ & $12,5 \%$ \\
\hline & \multirow[t]{2}{*}{ Ukupno } & $\mathrm{N}$ & 93 & 99 & 192 \\
\hline & & $\%$ & $100,0 \%$ & $100,0 \%$ & $100,0 \%$ \\
\hline
\end{tabular}


Tablica 2. Programi obrazovanja i usavršavanja menadžera vezan uz proširenje znanja

\begin{tabular}{|c|c|c|c|c|}
\hline \multirow{2}{*}{\multicolumn{2}{|c|}{$\begin{array}{l}\text { Kada bi Vam sada bilo ponuđeno da } \\
\text { pohađate neki program obrazovanja i } \\
\text { usavršavanja, odabrali biste program } \\
\text { koji bi bio vezan uz proširenje kojih } \\
\text { znanja: }\end{array}$}} & \multicolumn{3}{|c|}{ Djelatnosti po NKD-u } \\
\hline & & \multirow{2}{*}{$\begin{array}{l}\text { UZR } \\
44\end{array}$} & \multirow[t]{2}{*}{\begin{tabular}{|l|} 
OD \\
48
\end{tabular}} & \multirow[t]{2}{*}{\begin{tabular}{|l|} 
Ukupno \\
\\
92
\end{tabular}} \\
\hline \multirow[t]{6}{*}{ Stručnih znanja } & \multirow[t]{2}{*}{$\mathrm{Da}$} & & & \\
\hline & & $47,3 \%$ & $48,5 \%$ & $47,9 \%$ \\
\hline & \multirow[t]{2}{*}{$\mathrm{Ne}$} & 49 & 51 & 100 \\
\hline & & $52,7 \%$ & $51,5 \%$ & $52,1 \%$ \\
\hline & \multirow[t]{2}{*}{ Ukupno } & 93 & 99 & 192 \\
\hline & & $100,0 \%$ & $100,0 \%$ & $100,0 \%$ \\
\hline \multirow[t]{6}{*}{ Ekonomskih znanja } & \multirow[t]{2}{*}{$\mathrm{Da}$} & 11 & 34 & 45 \\
\hline & & $11,8 \%$ & $34,3 \%$ & $23,4 \%$ \\
\hline & \multirow[t]{2}{*}{$\mathrm{Ne}$} & 82 & 65 & 147 \\
\hline & & $88,2 \%$ & $65,7 \%$ & $76,6 \%$ \\
\hline & \multirow[t]{2}{*}{ Ukupno } & 93 & 99 & 192 \\
\hline & & $100,0 \%$ & $100,0 \%$ & $100,0 \%$ \\
\hline \multirow[t]{6}{*}{ Organizacijskih znanja } & \multirow[t]{2}{*}{$\mathrm{Da}$} & 31 & 39 & 70 \\
\hline & & $33,3 \%$ & $39,4 \%$ & $36,5 \%$ \\
\hline & \multirow[t]{2}{*}{$\mathrm{Ne}$} & 62 & 60 & 122 \\
\hline & & $66,7 \%$ & $60,6 \%$ & $63,5 \%$ \\
\hline & \multirow[t]{2}{*}{ Ukupno } & 93 & 99 & 192 \\
\hline & & $100,0 \%$ & $100,0 \%$ & $100,0 \%$ \\
\hline \multirow{6}{*}{$\begin{array}{l}\text { Znanja iz područja } \\
\text { menadžmenta }\end{array}$} & \multirow[t]{2}{*}{$\mathrm{Da}$} & 57 & 63 & 120 \\
\hline & & $61,3 \%$ & $63,6 \%$ & $62,5 \%$ \\
\hline & \multirow[t]{2}{*}{$\mathrm{Ne}$} & 36 & 36 & 72 \\
\hline & & $38,7 \%$ & $36,4 \%$ & $37,5 \%$ \\
\hline & \multirow[t]{2}{*}{ Ukupno } & 93 & 99 & 192 \\
\hline & & $100,0 \%$ & $100,0 \%$ & $100,0 \%$ \\
\hline \multirow[t]{6}{*}{ Informatičkih znanja } & \multirow[t]{2}{*}{$\mathrm{Da}$} & 39 & 44 & 83 \\
\hline & & $41,9 \%$ & $44,4 \%$ & $43,2 \%$ \\
\hline & \multirow[t]{2}{*}{$\mathrm{Ne}$} & 54 & 55 & 109 \\
\hline & & $58,1 \%$ & $55,6 \%$ & $56,8 \%$ \\
\hline & \multirow[t]{2}{*}{ Ukupno } & 93 & 99 & 192 \\
\hline & & $100,0 \%$ & $100,0 \%$ & $100,0 \%$ \\
\hline \multirow[t]{5}{*}{ Socioloških znanja } & \multirow[t]{2}{*}{$\mathrm{Da}$} & 10 & 17 & 27 \\
\hline & & $10,8 \%$ & $17,2 \%$ & $14,1 \%$ \\
\hline & \multirow[t]{2}{*}{$\mathrm{Ne}$} & 83 & 82 & 165 \\
\hline & & $89,2 \%$ & $82,8 \%$ & $85,9 \%$ \\
\hline & Ukupno & 93 & 99 & 192 \\
\hline
\end{tabular}




\begin{tabular}{|c|c|c|c|c|}
\hline & & $100,0 \%$ & $100,0 \%$ & $100,0 \%$ \\
\hline \multirow[t]{6}{*}{ Znanja iz psihologije } & \multirow[t]{2}{*}{$\mathrm{Da}$} & 18 & 37 & 55 \\
\hline & & $19,4 \%$ & $37,4 \%$ & $28,6 \%$ \\
\hline & \multirow[t]{2}{*}{$\mathrm{Ne}$} & 75 & 62 & 137 \\
\hline & & $80,6 \%$ & $62,6 \%$ & $71,4 \%$ \\
\hline & \multirow[t]{2}{*}{ Ukupno } & 93 & 99 & 192 \\
\hline & & $100,0 \%$ & $100,0 \%$ & $100,0 \%$ \\
\hline \multirow[t]{6}{*}{ Znanja ophođenja s ljudima } & \multirow[t]{2}{*}{$\mathrm{Da}$} & 51 & 56 & 107 \\
\hline & & $54,8 \%$ & $56,6 \%$ & $55,7 \%$ \\
\hline & \multirow[t]{2}{*}{$\mathrm{Ne}$} & 42 & 43 & 85 \\
\hline & & $45,2 \%$ & $43,4 \%$ & $44,3 \%$ \\
\hline & \multirow[t]{2}{*}{ Ukupno } & 93 & 99 & 192 \\
\hline & & $100,0 \%$ & $100,0 \%$ & $100,0 \%$ \\
\hline
\end{tabular}

\section{RASPRAVA}

Iako u svijetu postoje određena istraživanja na ovu temu, ali primarno u području vrhunskog sporta, u Hrvatskoj ovakva istraživanja još nisu provedena. Ovo je prvo istraživanje koje se bavi analizom i onda edukacijom menadžera u kineziološkoj rekreaciji. Ono daje dodatan doprinos postojećim teorijama i praksi menadžera $\mathrm{u}$ kineziološkoj rekreaciji. Također, to je prvo istraživanje provedeno kod nas koje uspoređuje menadžment $u$ kineziološkoj rekreaciji i menadžment u drugim djelatnostima te potrebna znanja menadžera u navedena dva sektora. Upravo komparativni pristup problematici još više ističe važnost educiranja menadžera koji rade na području kineziološke rekreacije.

Rezultati ovog istraživanja ukazuju na dva ključna problema kod menadžera koji rade u domeni kineziološke rekreacije. Prvo, učestalost kontinuirane edukacije je značajno niža u odnosu na menadžere drugih djelatnosti. Drugo, njihova motiviranost za daljnjim usavršavanjem je niža u svim segmentima (stručnom, ekonomskom, organizacijskom, menadžmentu, informatičkom, sociološkom, psihološkom i ophođenju s ljudima), a naročito u ekonomskom u odnosu ostale menadžere.

U Hrvatskoj stručno usavršavanje menadžera i djelatnika imaju najčešće poduzeća u inozemnom ili mješovitom vlasništvu koji za svoje menadžere organiziraju sustavne programe usavršavanja u matičnoj zemlji ili ih šalju u neke podružnice po svijetu (Bahtijarević-Šiber, Sikavica, 2002). U već spomenutom istraživanju Draganova (2016) rezultati su pokazali da sportski menadžeri imaju dovoljno stručnog i tehničkog znanja, ali im je potrebno znanje iz područja ekonomije. Drugi autori (Hoye i sur. (2015), Masteralexis i sur. (2011)) stavljaju naglasak na ekonomske teme u kontekstu sportskog menadžmenta. Oni naglašavaju da sportski menadžeri trebaju biti osposobljeni napraviti proračun koji prikazuje sve troškove, ali i izvore financiranja. Sportski menadžeri moraju biti financijski osviješteni i razumjeti financijske pokazatelje kako bi razumjeli financijsko stanje kompletne organizacije. Bez kvalitetne financijske podloge teško će se 
ostvariti vrhunski sportski rezultati. Ne samo ovo istraživanje, već i razgovor s nekolicinom ispitanika iz UZR neminovno potvrđuju potrebu za ekonomskim znanjima kod menadžera u kineziološkoj rekreaciji.

Pitanje učinkovitosti i kvalitete obrazovanja postaje sve više u prvom planu prakse upravljanja. Suština obrazovanja je pomoći menadžerima da nauče, razviju i poboljšaju svoje znanje i vještine. Načini obrazovanja menadžera jedan su od najvažnijih alata za osiguravanje procesa učenja (Milistenferova i sur, 2017). Opseg programa obrazovanja menadžera povezan je sa ciljevima u vezi s njihovim razvojem, planiranjem i provođenjem programa, administracijom, rješavanjem problema, profesionalnim razvojem menadžera te vrednovanjem menadžera (Ibrahim i Mazin, 2017). Osnovni dijelovi vrijednog programa obuke zaposlenika izgrađeni su na orijentaciji, menadžerskim vještinama i operativnim vještinama zaposlenika (Kleiman, 2000). Programi razvoja zaposlenika moraju sastojati od jezgre stručnosti, odgovarajuće strukture preko koje organizacije razvijaju svoje poslovanje na korporativnoj razini. Osnovna funkcija teorije je stjecanje znanja, suradnje, inventivnog razmišljanja i rješavanje problema (Kottke, 1999). Temeljni ciljevi nekoliko programa razvoja zaposlenika su pružiti misiju organizacije i pružiti podršku radnicima da nauče kulturu organizacije (Gerbman, 2000). Ovi ciljevi pomažu strateškim ciljevima poslovanja olakšavajući šanse za učenje i podržavaju organizacijsku kulturu (Kottke, 1999). Konačno, postoji potreba za sustavnijom organizacijom obrazovnih i edukacijskih programa vezanih uz različite razine menadžmenta u kineziološkoj rekreaciji (Freericks, 2010).

Zaposlenike treba ažurirati sadašnjim znanjem o poslu, pa će samim time i menadžeri biti produktivniji ako im poduzeća pruže obuku prema zahtjevnosti njihovog posla. Program obuke i razvoja planirana je obrazovna komponenta i s izuzetnom metodom dijeljenja kulture organizacije koja se kreće od jedne radne vještine do razumijevanja vještina na radnom mjestu, razvijanja vodstva, inovativnog razmišljanja i rješavanja problema (Meister, 1998). Programi za razvoj i obrazovanje menadžera uključuju razne nastavne tehnike, raspored rada i okruženje koje pomažu učenju koji osiguravaju zaposleniku da unaprijedi svoje vještine (Gerbamn, 2000).

Istraživački proces je bio limitiran veličinom uzorka uzrokovan Zakonom o zaštiti osobnih podataka (NN 42/18) i brojem zaposlenih koji je bio na donjoj granici traženog pogotovo u djelatnostima vezanima uz kineziološku rekreaciju.

\section{ZAKLJUČAK}

Rezultati istraživanja su pokazali kako menadžeri u ostalim djelatnostima učestalije pohađaju program obrazovanja unutar poduzeća u odnosu na menadžere u rekreaciji, te kako menadžeri u rekreaciji zapravo ne iskazuju dodatnu potrebu za programima obrazovanja iz područja ekonomskih znanja. Novitet i vrijednost ovog istraživanja ukazuje upravo na važnost edukacije menadžera općenito i razvijanje svjesnosti o ekonomskim znanjima koja imaju ključnu ulogu u uspješnom upravljanju kineziološko-rekreacijskom organizacijom. Time će se zasigurno doprinijeti kako 
obujmu tako i kvaliteti znanstvenih istraživanja iz područja rekreacije, ali i menadžmenta. Pored navedenog, rezultati istraživanja ukazuju na potrebu za prilagodbom postojećih i razvojem novih programa edukacije menadžera u području kineziološke rekreacije.

\section{LITERATURA:}

1. Andrijašević, M. (2010). Kineziološka rekreacija. Zagreb: Sveučilište u Zagrebu

2. Apitzsch, T., (2012). Kompetenzprofile von Trainern und Sportmanagern im Leistungssport, Deutsche Sporthochschule Köln.

3. Bahtijarević-Šiber, F. , Sikavica, P. (2002). Leksikon menadžmenta. Zagreb: Avantis d.o.o.

4. Bartoluci, M., Škorić, S. (2009). Menadžment u sportu. Zagreb: Odjel za izobrazbu trenera Društvenog veleučilišta u Zagrebu i Kineziološki fakultet

5. De Sensi, J.T., Kelley, D.R., Blanton, M.D., Beitel, P.A. (1990). Sport Management Curricular Evaluation and Needs Assessment: a multifaceted Approach, Journal of Sport Management, 4 (1), str. 31-58.

6. Draganov, G. (2016). Study of personal characteristics, competencies and skills of managers in sport business entities, Research in Kinesiology, 44 (2), str. 232237.

7. Drucker, P. (1961). Praksa rukovođenja. Zagreb: Privreda

8. Drucker, P. (1998). Die Praxis des Managements. Zürich: Dew

9. Fayol, H. (1949). General and industrial management. London: Pitman

10. Freericks, R., Harman, R., Stecker, B. und Mitarbeiter, (2010). Feizeitwissenschaft. München: Oldenburg Verlag

11. Gerbman, R. V. (2000). Corporate Universities 101, HR Magazine, 45 (2), str. 101-106.

12. Hoye, R., Smith, A.C., Nicholson, M., Stewart (2015). Sport management: Principles and Applications. New York: Routledge

13. Ibrahim, A A., Mazin, S. A. (2017). Educational Management, Educational Administration and Educational Leadership: Definitions and General concepts, SAS Journal of Medicine, 3 (12), str. 326-39.

14. Kleiman, M. (2000). What happens if you don't train them and they stay?, Occupational Health and Safety, 69 (1), str. 18-70.

15. Koontz, H., Weihrich H. and associates (1998). Knowledge Acquisition through International Strategic Alliances. New York: Academy of Management Executive

16. Kottke, J. L. (1999). Corporate universities: Lessons in building a world-class work force (revised), Personnel Psychology, 52 (1), str. 530-533.

17. Lussier, R.N., Kimball, D.C. (2014). Applied Sport Management Skills. London: Human Kinetics

18. Masteralexis, L., Barr, C., Hums, M. (2011). Principles and Practice of Sport Management. New York: Jones \& Bartlett Publishers 
19. Meister, J. C. (1998). Ten steps to creating a corporate university, Training and Development, 52 (11), str. 38-43.

20. Milistenferova, E., Socha, L., Tobisova, A., Socha, V. (2017). Application of Methods of Management Education in the Selected Organization, Magazine of Aviation Development, 5 (3), str. 18-23.

21. Pitts, B., Danylchuk, K., Quarterman, J. (2014). Analysis of Sport Management Literature: European Sport Management Quarterly, Sport Management International Journal, 10(2), str. 45-72.

22. Quarterman, J. i Li, M. (1998). Managing Sport Organizations. U J.B. Parks, B.R.K. Zanger, J. Quarterman (ur.), Contemporary Sport Management (str. 103118). Champaign: Human Kinetics.

23. Zakon o provedbi Opće uredbe o zaštiti podataka, NN 42/18 


\section{COMPARATIVE ANALYSIS OF MANAGERIAL EDUCATION IN KINESIOLOGICAL RECREATION AND OTHER ACTIVITIES}

\section{Summary}

Objectives: To compare the education of managers in kinesiological recreation (UZR) in relation to managers in other activities (OD) and to determine whether they want to improve their knowledge more.

Methodology: 192 respondents (66.7\% men, average age 40 years) are persons in leading positions in organizations. They were classified into two groups (UZR, OD) and surveyed using a modified questionnaire according to basic information about the manager (gender, age, level of education, level of management, length of service) and frequency of attending training programs (none, once, several times, constantly) and motivation to continue training (professional, economic, organizational, management, information, sociological, psychological and dealing with people).

Results: according to the frequency of attending educational programs within the company, the biggest difference between the groups is among those participants who constantly attended educational programs in favor of OD (3.2\% vs. 21.2\%). According to the program of continuing education and training of managers, the biggest difference between the groups is in the desire to acquire economic knowledge (11.8\% vs 34.3\%), and slightly less in the field of psychological (19.4\% vs 37.4\%) and sociological knowledge (10.8\% vs $17.2 \%)$ in benefit of OD group managers (for all $P<0.05$ ).

Limitation: The research process was limited by the sample size caused by the Personal Data Protection Act and the number of employees that was at the lower limit required especially in activities related to kinesiological recreation.

Originality and scientific contribution: The first research in Croatia that compares the current and motivation for future education of managers in kinesiological recreation and other activities. The novelty and value of this research indicates the importance of educating managers in general and developing awareness of economic knowledge that plays a key role in the successful management of kinesiology and recreation organization.

Key words: economic knowledge, management, managerial knowledge, kinesiological recreation, educational programs. 